\title{
Reproducibility of the six-minute walk test and Glittre ADL-test in patients hospitalized for acute and exacerbated chronic lung disease
}

\author{
Anderson José ${ }^{1}$, Simone Dal Corso ${ }^{1}$
}

\begin{abstract}
Background: The 6-minute walk test (6MWT) and the Glittre ADL-test (GT) are used to assess functional capacity and exercise tolerance; however, the reproducibility of these tests needs further study in patients with acute lung diseases. Objectives: The aim of this study was to investigate the reproducibility of the 6MWT and GT performed in patients hospitalized for acute and exacerbated chronic lung diseases. Method: $48 \mathrm{~h}$ after hospitalization, 81 patients (50 males, age: $52 \pm 18$ years, $\mathrm{FEV}_{1}: 58 \pm 20 \%$ of the predicted value) performed two 6MWTs and two GTs in random order on different days. Results: There was no difference between the first and second 6MWT (median $349 \mathrm{~m}$ [284-419] and $363 \mathrm{~m}$ [288-432], respectively) (ICC: 0.97; P<0.0001). A difference between the first and second tests was found in GT (median $286 \mathrm{~s}$ [220-378] and $244 \mathrm{~s}$ [197-323] respectively; $\mathrm{P}<0.001$ ) (ICC: 0.91; $\mathrm{P}<0.0001$ ). Conclusion: Although both the 6MWT and GT were reproducible, the best results occurred in the second test, demonstrating a learning effect. These results indicate that at least two tests are necessary to obtain reliable assessments.
\end{abstract}

Keywords: physical therapy; reproducibility of results; exercise tolerance; exercise test; lung diseases.

\section{HOW TO CITE THIS ARTICLE}

José A, Dal Corso S. Reproducibility of the six-minute walk test and Glittre ADL-test in patients hospitalized for acute and exacerbated chronic lung disease. Braz J Phys Ther. 2015 May-June; 19(3):235-242. http://dx.doi.org/10.1590/bjpt-rbf.2014.0092

\section{Introduction}

Clinical field tests are used to assess the functional capacity (FC) and exercise tolerance of patients with pulmonary diseases. It is important to know the reproducibility of these tests to achieve an accurate assessment of the patient's FC and responsiveness to treatment ${ }^{1}$. The variability of a test must also be known so that its results are reliable; this ensures the differences are due to interventions or the evolution of the patient rather than fluctuations inherent to the test.

The 6-minute walk test (6MWT) is a simple and low-cost field test that provides a comprehensive and integrated measure of the patient's physical condition ${ }^{2}$. The reproducibility of the 6MWT has been tested in patients with various lung diseases, particularly patients with chronic obstructive pulmonary disease $(\mathrm{COPD})^{3-5}$ mainly in the outpatient setting. The variability found in these studies has been attributed to a learning effect. A recent study found a difference of $27 \mathrm{~m}$ $(7 \%)$ greater in the second test ${ }^{6}$. Sciurba et al. ${ }^{7}$ found a difference of $20 \mathrm{~m} \mathrm{(7 \% ),} \mathrm{Chatterjee} \mathrm{et} \mathrm{al.}{ }^{8}$ found a 32-m difference (10\%), Stevens et al. ${ }^{9}$ found $42 \mathrm{~m}$ $(13 \%)$, and Jenkins and Cecins ${ }^{10}$ identified a $37-\mathrm{m}$ difference (11\%).
The reproducibility of the 6MWT has also been studied in patients with idiopathic interstitial pneumonia (ICC: 0.98 , standard deviation/mean: $4.2 \%)^{11}$, cystic fibrosis $(6.5 \mathrm{~m} \text { or } 4.3 \%)^{12}$, interstitial lung disease $(41 \mathrm{~m}, 10 \%)^{10}$, bronchiectasis $(22 \mathrm{~m}, 4 \%)^{10}$, and asthma $(19 \mathrm{~m}, 4 \%)^{10}$.

The Glittre ADL-test (GT) is another field test developed to evaluate the capacity to perform activities of daily living (ADL). Its reproducibility was tested in patients with COPD, showing a decrease of $22 \mathrm{~s}$ in the time to completion in the second test, which was attributed to a learning effect ${ }^{13}$.

Considering the importance of field-testing in clinical practice, its reproducibility should also be solidly studied in hospitalized patients not only with exacerbation of COPD but also with acute lung conditions, such as community-acquired pneumonia (CAP). To our knowledge, there is no study testing the reproducibility of the 6MWT and GT in hospitalized patients. The ability of the GT to detect exercise-induced desaturation, as previously demonstrated with the 6MWT in COPD ${ }^{14}$, should be assessed so that it can be used to identify patients with hypoxemia during 
ADL. The aim of this study was to investigate the reproducibility of the 6MWT and GT in patients hospitalized for acute and exacerbated chronic lung diseases and to compare the desaturation induced by both tests.

\section{Method}

\section{Participants}

The sample from a cross-sectional study previously published by our group ${ }^{15}$ was used for this current work. The sample included 103 adult patients hospitalized for less than $48 \mathrm{~h}$ for acute or exacerbated chronic lung diseases, with or without oxygen supplementation and without comorbidities that might limit their performances on the tests. For better characterization of the sample, patients were divided into three groups according to the most prevalent diseases of hospitalization in our hospital: CAP, COPD, and Others (other lung diseases). This study was approved by the Research Ethics Committee of Universidade Nove de Julho, São Paulo, Brazil (protocol no. 273811/2009). All patients signed an informed consent form.

\section{Design}

The study was conducted in two visits on consecutive days. On the first visit, spirometry was performed, the body mass index (BMI) was calculated, and dyspnea was assessed according to the Medical Research Council (MRC) scale. The randomization was performed using sealed and opaque envelopes that each contained a card indicating the 6MWT or GT. A person uninvolved in the research selected one of these envelopes, which determined which test would be performed first (6MWT or GT).

An hour of rest was allowed between testing and retesting. On the second visit ( $24 \mathrm{~h}$ apart), the other test was performed. The total period of hospitalization was recorded.

\section{Assessments}

\section{Spirometry}

Spirometry was performed with the Pony portable spirometer (COSMED, Italy). The acceptability and reproducibility criteria adopted for the technical procedures were those recommended by the Brazilian guidelines for the testing of lung function ${ }^{16}$. The values of forced vital capacity (FVC), forced expiratory volume in the first second $\left(\mathrm{FEV}_{1}\right)$, and the $\mathrm{FEV}_{1} / \mathrm{FVC}$ ratio were expressed in absolute values and as percentage of the predicted value for the Brazilian population ${ }^{17}$.

\section{Body mass index}

BMI was calculated by dividing the body weight of the patient in kilograms $(\mathrm{kg})$ by the square of the height in square meters $\left(\mathrm{m}^{2}\right)$, and the result was expressed in $\mathrm{kg} / \mathrm{m}^{2}{ }^{18}$. The patient was classified as underweight if $\mathrm{BMI}<18.5 \mathrm{~kg} / \mathrm{m}^{2}$, normal weight if $18.5-24.9 \mathrm{~kg} / \mathrm{m}^{2}$, overweight if $25-29.9 \mathrm{~kg} / \mathrm{m}^{2}$, and obese if $\mathrm{BMI}>30 \mathrm{~kg} / \mathrm{m}^{2} 19$.

\section{Medical Research Council's dyspnea scale}

The Medical Research Council's (MRC) scale of dyspnea includes five items. The patient chooses which of the items corresponds to the perceived limitations of dyspnea on his/her ADLs. The patient selects a value from 1-5; the higher the score the greater the limitations dyspnea imposes on the patient's $\mathrm{ADL}^{20}$.

\section{Six-minute walk test (6MWT)}

The 6MWT was performed on a 20-meter-long flat corridor. Two tests with 1-h rest times were performed on the same day. Other procedures and standardizations were performed according to the American Thoracic Society recommendations ${ }^{2}$. The test with the longest distance walked was selected for analysis, and the distance walked was expressed in $\mathrm{m}$ and predicted values ${ }^{21}$. Heart rate (HR) and oxyhemoglobin saturation $\left(\mathrm{SpO}_{2}\right)$ were measured at rest, at $3 \mathrm{~min}$, and at the end of the test using a pulse oximeter (Nonin 9500 model, Minnesota, United States). The scores for sensation of dyspnea (Borg D) and lower limb fatigue (Borg LL) were measured at rest and at the end of the test according to the modified Borg scale ${ }^{22}$.

Evaluation of oxygen desaturation was also obtained from the longest test considering the lowest $\mathrm{SpO}_{2}$ recorded. Oxygen supplementation, when necessary, was maintained in accordance with the prescription of the medical team. A covered distance $<82 \%$ of the predicted value was considered below normal ${ }^{23}$.

\section{Glittre ADL-test (GT)}

The GT comprises a circuit of functional activities the patient must cover 5 times in the shortest time possible. The patient performs activities such as walking, using stairs, sitting on a chair and standing up, and handling 1-kg weights to simulate moving 
objects from one shelf to another and then to the floor. Throughout the test, the patient wears a weighted backpack $^{13}$.

Two tests were performed on the same day, with a 1-h rest interval between them. $\mathrm{HR}, \mathrm{SpO}_{2}$, and time to completion were measured at rest and at the end of each completed lap. The Borg D and Borg $\mathrm{LL}^{22}$ scores were also evaluated at rest and at the end of the test. The test's total time to completion was recorded at the end.

Evaluation of oxygen desaturation was obtained from the test with the shorter duration considering the lowest $\mathrm{SpO}_{2}$ recorded. As described for 6MWT, oxygen supplementation, when necessary, was maintained in accordance with the prescription of the medical team.

\section{Statistical analysis}

The data analysis was performed using SPSS for Windows version 20.0 (SPSS, Chicago, Illinois, USA). The Shapiro-Wilk test was used to verify the compliance of the data distribution with the normality curve. Parametric data were express ed as mean and SD. Non-parametric data were expressed as median and interquartile intervals. In the sample characterization, comparisons between groups were performed by one-way analysis of variance (ANOVA) with post-hoc Tukey's analysis. Interclass correlation coefficient and Bland-Altman analysis were used for test-retest reproducibility. Intragroup comparisons for parametric data were performed by paired $t$-tests for dependent samples, and by the Wilcoxon test for the non-parametric data. $\mathrm{P}<0.05$ was considered statistically significant.

\section{Results}

\section{Sample}

Of the 103 patients enrolled in the study, 10 were excluded for failure to perform the 6MWT and 12 for failure to perform the GT because of hospital discharge. At the end of the study, 81 subjects (50 men) were surveyed.

Fifty-one patients (63\%) had a diagnosis of CAP, 16 patients $(20 \%)$ were diagnosed with exacerbated COPD, and 14 (17\%) were diagnosed with other diseases (lung cancer $=7$, asthma $=4$, and tuberculosis $=3$ ). According to BMI, 3 patients (4\%) were classified as underweight, 39 (48\%) as normal weight, 19 (23\%) as overweight, and $20(25 \%)$ as obese.

The patients with CAP were younger than those in the COPD group $(\mathrm{P}<0.0001)$. Additionally, $\mathrm{BMI}$ and dyspnea were higher in the COPD group compared with patients in the CAP group (all $\mathrm{P}<0.05$ ). The hospitalization period did not differ between groups. Spirometry differed among groups (Table 1).

Table 1. Characteristics of the studied patients.

\section{Variables}

Demographic data and BMI

Age, years

BMI, $\mathrm{Kg} / \mathrm{m}^{2}$

Pulmonary function

FVC, L

FVC, $\%$ of the predicted value

$\mathrm{FEV}_{1}$, L

$\mathrm{FEV}_{1}, \%$ of the predicted value

$\mathrm{FEV}, / \mathrm{FVC}, \%$

Dyspnea

MRC scale

\section{Hospitalization}

Time of hospitalization, days
$2.1 \pm 0.8$

$\operatorname{CAP}(n=51)$

$47 \pm 17 *$

$25 \pm 4 \#$

$55.7 \pm 17.4$

$1.8 \pm 0.7^{\text {\# }}$

$58.5 \pm 17.9^{\text {\# }}$

$88.5(78.0-93.4)^{* \bullet}$

$2(2-4)^{\#}$

$13(8-16)$

\section{Results}

COPD (n=16)

Others $(n=4)$

$66 \pm 9$

$29 \pm 6^{\prime \prime}$

$1.8 \pm 0.7$

$2.6 \pm 0.9$

$53 \pm 19.4=$

$74.9 \pm 17.4$

$1.1 \pm 0.4$

$2.0(1.3-2.7)$

$42.8 \pm 16.2$

$72.1 \pm 22.7 *$

$66.6(57.5-69.2)$

$75.2 \pm 15.9$

CAP: community-acquired pneumonia; COPD: chronic obstructive pulmonary disease; BMI: body mass index; $\mathrm{Kg} / \mathrm{m}^{2}$ : kilogram per square meter; L: liters; FVC: forced vital capacity; $\mathrm{FEV}_{1}$ : forced expiratory volume in the first second; MRC: Medical Research Council score. ${ }^{*} \mathrm{P}<0.0001$ compared to $\mathrm{COPD}$ group; ${ }^{\sharp} \mathrm{P}<0.05$ compared to COPD group; $\cdot \mathrm{P}<0.05$ compared to others group. 


\section{Reproducibility}

No significant difference was found in the distance covered between the two 6MWTs, with a 14-m increase in the second test ( $4 \%$ increase). 49 patients $(61 \%)$ covered a greater distance in the second test and 50 patients $(62 \%)$ had a difference of $<27 \mathrm{~m}$ between the two tests. HR, $\mathrm{SpO}_{2}$ and dyspnea, and lower limb fatigue scales were equivalent (Table 2).

In the GT, a 42-s difference was found in the second test $(17 \%$ increase, $\mathrm{P}<0.001)$, and 71 patients $(88 \%)$ performed the second test in less time than the first. As in the 6MWT, the $\mathrm{HR}, \mathrm{SpO}_{2}$ and dyspnea, and lower limb fatigue scales were equivalent in both tests (Table 3)

The Bland-Altman analysis reveals that the patients improved the distances covered in the second test of the 6MWT (Figure 1) and the GT (Figure 2), showing a narrow mean difference. However, the confidence interval of the means of the differences was wide, showing great variability of results between testing and retesting.

Table 2. Results for the 6MWT.

\begin{tabular}{|c|c|c|c|}
\hline Variables & 6MWT -1 & $6 \mathrm{MWT}-2$ & ICC $(95 \% \text { CI })^{*}$ \\
\hline \multicolumn{4}{|l|}{ Rest } \\
\hline $\mathrm{HR}$, bpm & $89 \pm 16$ & $91 \pm 17^{\sharp}$ & $0.94(0.90-0.96)$ \\
\hline $\mathrm{SpO}_{2}, \%$ & $96(95-98)$ & $96(95-98)$ & $0.87(0.79-0.91)$ \\
\hline Borg d & $0.5(0-1)$ & $0(0-0.75)^{\#}$ & $0.64(0.45-0.77)$ \\
\hline Borg LL & $0(0-0.5)$ & $0(0-1)$ & $0.84(0.76-0.90)$ \\
\hline \multicolumn{4}{|l|}{$3^{\text {rd. }}$ Minute } \\
\hline HR, bpm & $111(98-121)$ & $109(96-120)$ & $0.85(0.77-0.90)$ \\
\hline $\mathrm{SpO}_{2}, \%$ & $93(90-96)$ & $94(88-96)$ & $0.90(0.84-0.94)$ \\
\hline \multicolumn{4}{|l|}{$6^{\text {th. }}$ Minute } \\
\hline HR, bpm & $113(100-123)$ & $112(102-122)$ & $0.87(0.82-0.93)$ \\
\hline $\mathrm{SpO}_{2}, \%$ & $94(90-97)$ & $94(89-96)$ & $0.92(0.87-0.95)$ \\
\hline Borg d & $1(0-3)$ & $0.5(0-2.5)^{\#}$ & $0.88(0.81-0.93)$ \\
\hline Borg LL & $0.5(0-2.5)$ & $0(0-2)$ & $0.93(0.89-0.95)$ \\
\hline Distance, $\mathrm{m}$ & $349(285-419)$ & $363(288-432)$ & $0.97(0.95-0.98)$ \\
\hline
\end{tabular}

6MWT-1: first six-minute walk test; 6MWT-2: second six-minute walk test; bpm: beats per minute; Borg d: Borg scale for dyspnea; Borg 11; Borg scale for lower limb fatigue; m: meters. ${ }^{*} \mathrm{P}<0.0001$ for all variables; ${ }^{\sharp} \mathrm{P}<0.05$ in relation to the 6MWT-1.

Table 3. Results for the Glittre ADL-test.

\begin{tabular}{ccccc}
\hline \multirow{2}{*}{ Rest } & Variables & GT $\mathbf{- 1}$ & GT $-\mathbf{2}$ & ICC (95\% CI)* \\
& & & & $0.92(0.87-0.95)$ \\
& $\mathrm{HR}, \mathrm{bpm}$ & $90(78-101)$ & $92(82-105)^{\#}$ & $0.83(0.74-0.89)$ \\
& $\mathrm{SpO}_{2}, \%$ & $97(96-98)$ & $97(96-98)$ & $0.80(0.68-0.87)$ \\
& Borg d & $0(0-0.5)$ & $0(0-0.5)$ & $0.67(0.48-0.79)$ \\
& Borg LL & $0(0-0.5)$ & $0(0-1)$ & $0.87(0.80-0.92)$ \\
& & & $126 \pm 19$ & $0.88(0.81-0.92)$ \\
& $\mathrm{HR}, \mathrm{bpm}$ & $126 \pm 19$ & $94(91-97)$ & $0.86(0.78-0.91)$ \\
& $\mathrm{SpO}, \%$ & $94(91-97)$ & $2(1-4)$ & $0.80(0.69-0.87)$ \\
& Borg D & $3(1-4)$ & $244(197-323)$ & $0.91(0.75-0.96)$ \\
\hline
\end{tabular}

GT-1: first Glittre ADL-test; GT-2: second Glittre ADL-test; bpm: beats per minute; Borg D: Borg scale for dyspnea; Borg LL; Borg scale for lower limb fatigue; s: seconds. * $\mathrm{P}<0.001$ for all variables; ${ }^{-} \mathrm{P}<0.001$ in relation to GT1; ${ }^{\sharp} \mathrm{P}<0.05$ in relation to GT1. 


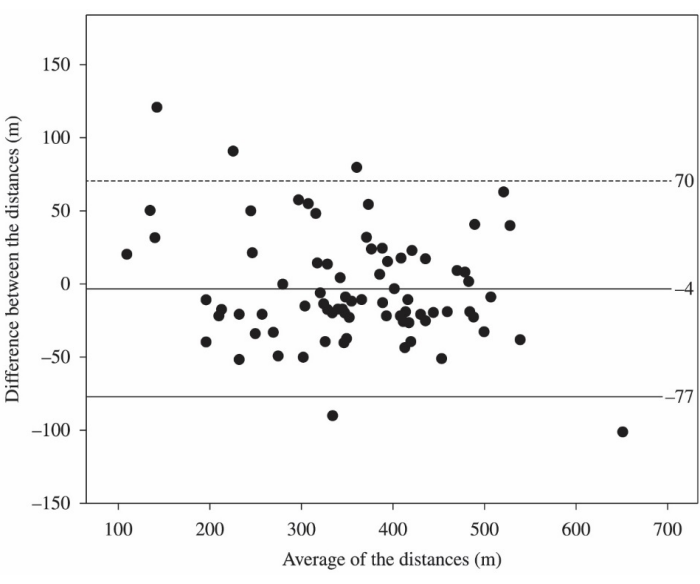

Figure 1. Bland-Altman of the average distance covered in the 6MWT and the difference between the distances in the two tests. The solid horizontal line represents the average polarization. The dashed horizontal lines represent the upper and lower limits of agreement.

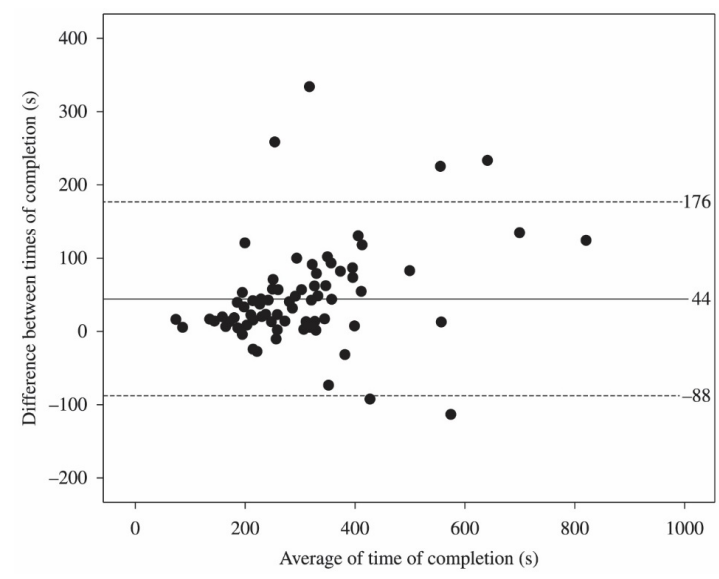

Figure 2. Bland-Altman of the average of time of completion of GT and the difference between the times of completion of the two tests. The dashed horizontal lines represent the upper and lower limits of agreement.

The distance covered in the best 6MWT was greater than $82 \%$ of the predicted value in 15 patients (19\%) (CAP: 60\%, COPD: 27\%, Others: 13\%) and smaller than $82 \%$ of the predicted value in 66 patients (81\%) (CAP: 64\%, COPD: 18\%, Others: 18\%). A comparison of these groups, respectively, showed that the older individuals ( $61 \pm 16$ and $50 \pm 17$ years, $\mathrm{P}<0.05)$ had higher BMIs $\left(28 \pm 4\right.$ and $\left.25 \pm 5 \mathrm{~kg} / \mathrm{m}^{2}, \mathrm{P}<0.05\right)$ and walked $453 \pm 83$ and $353 \pm 98 \mathrm{~m}$ in the $6 \mathrm{MWT}$ $(\mathrm{P}<0.0001)(96 \pm 17$ and $61 \pm 13 \%$ of the predicted value, $\mathrm{P}<0.0001)$. However, no differences were found in lung function, period of hospitalization, dyspnea scale or GT $(240 \pm 69 \mathrm{~s}$ and $282 \pm 126 \mathrm{~s}, \mathrm{P}=0.08)$.

There were no significant differences between the 6MWTs in $\mathrm{HR}$ and $\mathrm{SpO}_{2}$. The mean biases $(95 \% \mathrm{CI}$ of the differences) were $0\left(-23-23\right.$ beats $\left./ \mathrm{min}^{-1}\right)$ and $1(-5-6 \%)$ respectively; for the GT they were $-1\left(-19-18\right.$ beats $\left./ \mathrm{min}^{-1}\right)$ and $0(-6-5 \%)$ respectively.

In the separate evaluations of the reproducibility of the 6MWT in COPD and CAP patients, the results were as follows: COPD: $318 \pm 81$ and $328 \pm 84 \mathrm{~m}$, in the first and second test, respectively $(\mathrm{P}=0.18)$, mean bias $10 \mathrm{~m}$ (-44-64); ICC: 0.97 (0.91-0.99), $\mathrm{P}<0.0001$; CAP: $368 \pm 103$ and $366 \pm 113 \mathrm{~m}$, in the first and second tests respectively $(\mathrm{P}=0.84)$, mean bias $1 \mathrm{~s}(-78-80)$; ICC: 0.97 (0.94-0.98), $\mathrm{P}<0.0001$. In relation to the reproducibility of the GT in COPD and CAP patients, the results were as follows: COPD: $378 \pm 136$ and $302 \pm 115$ $\mathrm{s}$ in the first and second tests respectively $(\mathrm{P}=0.006)$, mean bias $77 \mathrm{~s}$ (-113-267); ICC: 0.75 (0.15-0.92), $\mathrm{P}=0.01$; CAP: $301 \pm 125$ and $264 \pm 110 \mathrm{~s}$ in the first and second tests respectively $(\mathrm{P}<0.0001)$, mean bias $37 \mathrm{~s}$ (-82-155); ICC: 0.91 (0.76-0.97), $\mathrm{P}<0.0001$.

\section{Comparison of oxyhemoglobin desaturation between the two test types}

The comparison between the lowest saturation on the best 6MWT and GT showed no significant differences $(\mathrm{P}=0.37)$ and were reproducible (ICC $=0.69$ (95\% CI: 0.51-0.80), $\mathrm{P}<0.0001)$. The mean bias $(95 \% \mathrm{CI})$ of the desaturation between 6MWT and GT was -0.4 (-9-8\%).

\section{Discussion}

This study examined the reproducibility of the 6MWT and GT in a sample of patients with acute and exacerbated chronic lung diseases. Both tests were reproducible. In the $6 \mathrm{MWT}$, most patients increased the distance covered in the second test (median variation: $14 \mathrm{~m}, 4 \%$ improvement); this was also found in GT, as most patients reduced the time to completion in the second test (median variation: $42 \mathrm{~s}, 17 \%$ lower), suggesting the presence of a learning effect. For both cases, the Bland-Altman analysis confirmed that the second test was better than the first, and the detected limits of agreement were higher than the upper limits of a clinically significant change; that is, changes of $26 \mathrm{~m}$ in the $6 \mathrm{MWT}^{24}$ and $53 \mathrm{~s}$ in the $\mathrm{GT}^{13}$.

While there is interest in the early rehabilitation of patients hospitalized for acute and chronic lung diseases, we were interested in investigating the reproducibility 
of the 6MWT and the GT since there are no studies on this group. Our results demonstrate that the variability in these conditions is similar to that observed in nonhospitalized patients with chronic lung conditions ${ }^{6}$.

It is common to find a large variability in field tests, which has been credited to the learning effect. In our study, this effect can be identified in the difference in time to perform the GT and the high variability observed by the large limits of agreement in both tests. However, the analysis of this effect is compromised because most studies commonly express the data as mean and SD, showing no variability between tests. In the present study, we employed the Bland-Altman method $^{25}$, which is considered a better analysis to compare the agreement of two measurements.

\section{Six-minute Walk Test (6MWT)}

In the first 6MWT, our patients walked a distance of $349 \mathrm{~m}(285-419)$. In the second test, the patients walked $363 \mathrm{~m}$ (288-432), representing a 14-m increase in the second test (4\% increase). This was less than the difference found in other studies ${ }^{6-12}$, resulting in an excellent correlation coefficient $(\mathrm{ICC}=0.97-95 \%$, CI $0.95-0.98 ; \mathrm{P}<0.001)$. The difference found in our study was lower than that suggested by Puhan et al. ${ }^{24}$, whose study was conducted among patients with stable COPD, suggesting a minimal clinically significant difference of $26 \mathrm{~m}$. The difference in our work was also lower than that suggested by Hernandes et al. ${ }^{6}$, whose study was also conducted among patients with stable COPD (difference of $27 \mathrm{~m}$ ). We found a difference of $<27 \mathrm{~m}$ between tests in 50 patients $(62 \%)$, which was reported as a clinically important difference by these researchers.

Despite the high test-retest variability by the Bland-Altman analysis (Figure 1), our data showed lower limits of agreement than those previously described using the same method of analysis (-67-120 $\mathrm{m}$ in the study by Hernandes et al. ${ }^{6}$ and $-77-70 \mathrm{~m}$ in our study). The high variability, which was also found in our study, was attributed to the learning effect, and supports the need to perform two 6MWTs. However, the extent to which the test-retest variability is representative of the learning effect remains unclear ${ }^{3-12}$. To illustrate the magnitude of the variability between the two walking tests carried out on the same day, we also cite a study from Puhan et al. ${ }^{24}$, which found a mean difference of $20 \pm 45 \mathrm{~m}$ pre-rehabilitation, which is higher than ours.

In addition to the learning effect already mentioned, we credit the variability found in our study to the heterogeneity of our sample, which comprised patients with several lung diseases. Additionally, there were also acute clinical situations among our patients that could predispose this population to clinical conditions, such as hyperthermia, active infection, cough, chest pain, dyspnea, muscle fatigue, tachycardia, myalgia, sweating, malnutrition, hypoxemia, and adynamia. The patient with chronic lung disease may also present some of these signs and symptoms. However, the patient with acute pulmonary disease presents with this clinical situation without the body, organic, and metabolic adaptations that develop in a patient with chronic disease over his or her lifetime, thereby making this clinical condition quite debilitating with respect to $\mathrm{FC}$ and exercise tolerance.

Hernandes et al. ${ }^{6}$ also investigated the determinants for a $>42 \mathrm{~m}$ distance covered in the second 6MWT. They concluded that a poor first 6 MWT $(<350 \mathrm{~m})$, Charlson index $<2$ points, or a BMI $<30 \mathrm{~kg} / \mathrm{m}^{2}$ were determinants. Sciurba et al. ${ }^{7}$ found that participants with higher maximal inspiratory pressures showed more marked improvements in the second walk.

\section{Glittre ADL-test (GT)}

Patients performed the first GT in a median of $286 \mathrm{~s}(220-378)$ and the second test in a median of $244 \mathrm{~s}$ (197-323), with a time difference of $42 \mathrm{~s}$ (17\% decrease) and a good correlation ( $\mathrm{ICC}=0.91-95 \%$, CI: $0.75-0.96 ; \mathrm{P}<0.001)$. The time to completion of the second test was closest to the time found in the study by Skumlien et al. ${ }^{13}$ conducted in patients with stable COPD (median $250 \mathrm{~s}$ ). In this study, 52 patients underwent two GTs to test its reproducibility. The test-retest difference was $22 \mathrm{~s}$ ( $7 \%$ decrease), which was attributed to the learning effect. As observed in our study, there were no differences in dyspnea and $\mathrm{SpO}_{2}$. It was not possible to compare our limits of agreement with this study because this type of analysis was not performed. It is interesting to note that, in another group of COPD patients that performed a pulmonary rehabilitation program, there was an improvement of $53 \mathrm{~s}$ in the test duration ${ }^{13}$, a post-treatment difference higher than ours (42 s).

Few studies beyond the original ${ }^{13}$ have used the GT as a field test. However, none of these studies provided test-retest measurements, therefore this test's reproducibility and variability was not established ${ }^{26-28}$.

We can raise the hypothesis of the learning effect to explain the great variability found in our study in addition to what has been previously described with the heterogeneity and the acute clinical condition of 
our sample. Just as it is common to find differences between the 6MWT that can be credited to the learning effect, the GT may also be influenced by this effect, as considered in another study ${ }^{13}$. This effect can be greater when compared with the effect shown in the 6MWT because this test has additional and more complex activities.

\section{Oxyhemoglobin desaturation between the two test types}

We also found that the changes in oxygen saturation measured by pulse oximeter were reproducible in both the 6MWT and GT. When comparing the lowest pulse oximetric saturation in the best 6MWT and best GT, we also found good equivalence; however, although the analysis using the Bland-Altman method showed a small mean of the differences, we observed large limits of agreement (-9-8\%). This wide dispersion of results can be credited to the heterogeneity of the studied sample, whose physiopathological changes may limit the individual's activities in different ways. For example, some patients may experience great difficulty in exercising the upper limbs, bending down and carrying weights (COPD), whereas others do not have much difficulty performing these activities (CAP and other diseases).

\section{Potential and implications of the study}

Although the reproducibility of the 6MWT has already been widely studied in the literature and the GT has already been described in COPD, our study was the first to assess the reproducibility of these tests in patients hospitalized for acute lung diseases, which are routinely found in hospital wards. Our study also showed a statistical analysis that yielded results of clinical importance, and it constituted not only the data of averages and differences but also the limits of agreement between the assessments.

The clinical implications of the findings in this study relate to the fact that the differences found in the clinical field tests may lead to erroneous interpretations of the FC examination of these patients. Our findings demonstrate that the results were better in the second test of both examinations surveyed, meaning that interpretations based on a first test would be inaccurate for the patient assessment, prescription, or responsiveness of a training program. Therefore, we recommend that at least two 6MWTs, as recommended by American Thoracic Society (ATS) ${ }^{2}$, and two GTs should be performed in patients hospitalized for acute or exacerbated chronic lung diseases.

\section{Limitations of the study}

This study has some limitations. First, the tests were not always performed by the same examiner; however, the testing was standardized ${ }^{2,13}$ and these examiners were trained. Moreover, to represent an acute pulmonary situation, the results are applicable to patients who were hospitalized at up to $48 \mathrm{~h}$. Nevertheless, we know that a patient can seek hospital care at the first symptoms of the disease while others wait until they have a significant worsening of symptoms, which could lead to a variability in clinical conditions among the sample population. Finally, we had to adjust the distance of the 6MWT for $20 \mathrm{~m}$ due to space constraints in the hospital environment.

\section{Conclusions}

The 6MWT and GT were reproducible in patients hospitalized for acute lung diseases, and most patients improved their scores on the second test. The detected variability was large and the limits of agreement exceeded the minimal clinically significant difference. Desaturation was similar between 6MWT and GT; therefore, the GT can be used to detect exercise-induced desaturation, and we speculate that the GT could also be used to identify patients who would present desaturation during ADL.

Our study showed that, in the evaluation of the FC of this group of patients, at least two tests of each examination are needed to obtain reliable and valid assessments.

\section{References}

1. ERS Task Force, Palange P, Ward SA, Carlsen KH, Casaburi R, Gallagher CG, et al. Recommendations on the use of exercise testing in clinical practice. Eur Respir J. 2007;29(1):185-209. http://dx.doi.org/10.1183/09031936.00046906. PMid:17197484

2. ATS Committee on Proficiency Standards for Clinical Pulmonary Function Laboratories. ATS statement: guidelines for the six-minute walk test. Am J Respir Crit Care Med. 2002;166(1):111-7. http://dx.doi.org/10.1164/ajrccm.166.1.at1102. PMid:12091180

3. Spruit MA, Watkins ML, Edwards LD, Vestbo J, Calverley PM, Pinto-Plata V, et al, Determinants of poor 6-min walking distance in patients with COPD: the ECLIPSE cohort. Respir Med. 2010;104(6):849-57. http://dx.doi. org/10.1016/j.rmed.2009.12.007. PMid:20471236

4. Puhan MA, Mador MJ, Held U, Goldstein R, Guyatt GH, Schünemann HJ. Interpretation of treatment changes in 6-minute walk distance in patients with COPD. Eur Respir J. 2008;32(3):637-43. http://dx.doi.org/10.1183/09031936.00140507. PMid:18550610 
5. Pinto-Plata VM, Cote C, Cabral H, Taylor J, Celli BR. The 6-min walk distance: change over time and value as a predictor of survival in severe COPD. Eur Respir J. 2004;23(1):28-33. http://dx.doi.org/10.1183/09031936.03.0 0034603. PMid: 14738227

6. Hernandes NA, Wouters EFM, Meijer K, Annegarn J, Pitta F, Spruit MA. Reproducibility of 6-minute walking test in patients with COPD. Eur Respir J. 2011;38(2):261-7. http:// dx.doi.org/10.1183/09031936.00142010. PMid:21177838

7. Sciurba F, Criner GJ, Lee SM, Mohsenifar Z, Shade D, Slivka $\mathrm{W}$, et al. Six-minute walk distance in chronic obstructive pulmonary disease: reproducibility and effect of walking course layout and length. Am J Respir Crit Care Med. 2003;167(11):1522-7. http://dx.doi.org/10.1164/rccm.200203166OC. PMid:12615634

8. Chatterjee AB, Rissmiller RW, Meade K, Paladenech C, Conforti J, Adair NE, et al. Reproducibility of the 6-minute walk test for ambulatory oxygen prescription. Respiration. 2010;79(2):121-7. http://dx.doi.org/10.1159/000220343. PMid:19468196

9. Stevens D, Elpern E, Sharma K, Szidon P, Ankin M, Kesten S. Comparison of hallway and treadmill six-minute walk tests. Am J Respir Crit Care Med. 1999;160(5 Pt 1):1540-3. http:// dx.doi.org/10.1164/ajrccm.160.5.9808139. PMid:10556117

10. Jenkins S, Cecins NM. Six-minute walk test in pulmonary rehabilitation: do all patients need a practice test? Respirology. 2010;15(8):1192-6. http://dx.doi.org/10.1111/j.14401843.2010.01841.x. PMid:20920121

11. Eaton T, Young P, Milne D, Wells AU. Six-minute walk, maximal exercise tests: reproducibility in fibrotic interstitial pneumonia. Am J Respir Crit Care Med. 2005;171(10):1150-7. http://dx.doi.org/10.1164/rccm.200405-578OC. PMid:15640367

12. Ziegler B, Rovedder PME, Oliveira CL, Abreu e Silva F, Tarso Roth Dalcin P. Repeatability of the 6-minute walk test in adolescents and adults with cystic fibrosis. Respir Care. 2010;55(8):1020-5. PMid:20667149.

13. Skumlien S, Hagelund T, Bjørtuft O, Ryg MS. A field test of functional status as performance of activities of daily living in COPD patients. Respir Med. 2006;100(2):316-23. http://dx.doi.org/10.1016/j.rmed.2005.04.022. PMid:15941658

14. Poulain M, Durand F, Palomba B, Ceugniet F, Desplan J, Varray A, et al. 6-minute walk testing is more sensitive than maximal incremental cycle testing for detecting oxygen desaturation in patients with COPD. Chest. 2003;123(5):14017. http://dx.doi.org/10.1378/chest.123.5.1401. PMid:12740254

15. José A, Corso SD. Patients hospitalized for communityacquired pneumonia present reduced functional performance. Braz J Phys Ther. 2013;17(4):351-8. http://dx.doi.org/10.1590/ S1413-35552013005000098. PMid:24072224

16. Sociedade Brasileira de Pneumologia e Tisiologia. Diretrizes para testes de função pulmonar. J Bras Pneumol. 2002;28(S3):S44-58.

17. Pereira CAC, Barreto SP, Simões JG, Pereira FWL, Gerstler JG, Nakatani J. Valores de referência para espirometria em uma amostra da população brasileira adulta. J Bras Pneumol. 1992;18(1):10-22.
18. World Health Organization - WHO. The world health report 2002: reducing risks, promoting health life. Geneva: WHO; 2002.

19. Associação Brasileira para o Estudo da Obesidade e da Síndrome Metabólica - ABESO. Sobrepeso e obesidade: diagnóstico. 3a ed. Itapevi, SP: AC Farmacêutica; 2009.

20. Kovelis D, Segretti NO, Probst VS, Lareau SC, Brunetto AF, Pitta F. Validação do Modified Pulmonary Functional Status and Dyspnea Questionnaire e da escala do Medical Research Council para o uso em pacientes com doença pulmonar obstrutiva crônica no Brasil. J Bras Pneumol. 2008;34(12):1008-18. http://dx.doi.org/10.1590/S180637132008001200005. PMid:19180335

21. Enright PL, Sherrill DL. Reference equations for the six-minute walk in healthy adults. Am J Respir Crit Care Med. 1998;158(5 Pt 1):1384-7. http://dx.doi.org/10.1164/ ajrccm.158.5.9710086. PMid:9817683

22. Wilson RC, Jones PW. A comparison of the visual analogue scale and modified Borg scale for the measurement of dyspnoea during exercise. Clin Sci (Lond). 1989;76(3):27782. PMid:2924519.

23. Troosters T, Gosselink R, Decramer M. Six minute walking distance in healthy elderly subjects. Eur Respir J. 1999;14(2):270-4. http://dx.doi.org/10.1034/j.13993003.1999.14b06.x. PMid:10515400

24. Puhan MA, Chandra D, Mosenifar Z, Ries A, Make B, Hansel $\mathrm{NN}$, et al. The minimal important difference of exercise tests in severe COPD. Eur Respir J. 2011;37(4):784-90. http:// dx.doi.org/10.1183/09031936.00063810. PMid:20693247

25. Bland JM, Altman DG. Statistical methods for assessing agreement between two methods of clinical measurement. Lancet. 1986;1(8476):307-10. http://dx.doi.org/10.1016/ S0140-6736(86)90837-8. PMid:2868172

26. Karloh M, Karsten M, Pissaia FV, Araujo CL, Mayer AF. Physiological responses to the Glittre-ADL test in patients with chronic obstructive pulmonary disease. J Rehabil Med. 2014;46(1):88-94. http://dx.doi.org/10.2340/16501977-1217. PMid:24104462

27. Valadares YD, Corrêa KS, Silva BO, Araujo CLP, Karloh M, Mayer AF. Applicability of activities of daily living tests in individuals with heart failure. Rev Bras Med Esporte. 2011;17(5):310-4. http://dx.doi.org/10.1590/ S1517-86922011000500003.

28. Corrêa KS, Karloh M, Martins LQ, Santos K, Mayer AF. Can the Glittre ADL test differentiate the functional capacity of COPD patients from that of healthy subjects? Rev Bras Fisioter. 2011;15(6):467-73. http://dx.doi.org/10.1590/S141335552011005000034. PMid:22094546

\section{Correspondence}

\section{Simone Dal Corso}

Rua Vergueiro, 235/249, $2^{\circ}$ subsolo CEP 01504-001,

São Paulo, SP, Brazil

e-mail: si.dal.corso@gmail.com 